\title{
Cocoa pod husk extract-mediated biosynthesis of silver nanoparticles: its antimicrobial, antioxidant and larvicidal activities
}

\author{
Agbaje Lateef $^{1} \cdot$ Musibau A. Azeez $^{1} \cdot$ Tesleem B. Asafa $^{2} \cdot$ Taofeek A. Yekeen $^{1}$. \\ Akeem Akinboro $^{1} \cdot$ Iyabo C. Oladipo $^{3} \cdot$ Luqmon Azeez $^{4} \cdot$ Sunday A. Ojo $^{1}$ • \\ Evariste B. Gueguim-Kana ${ }^{5} \cdot$ Lorika S. Beukes $^{6}$
}

Received: 23 February 2016/Accepted: 28 March 2016/Published online: 28 April 2016

(c) The Author(s) 2016. This article is published with open access at Springerlink.com

\begin{abstract}
The present investigation reports utility of cocoa pod husk extract (CPHE), an agro-waste in the biosynthesis of silver nanoparticles (AgNPs) under ambient condition. The synthesized CPHE-AgNPs were characterized by UVvisible spectroscopy, Fourier-transform infrared spectroscopy, Energy dispersive X-ray (EDX) spectroscopy and transmission electron microscopy. The feasibility of the CPHE-AgNPs as antimicrobial agent against some multidrug-resistant clinical isolates, paint additive, and their antioxidant and larvicidal activities were evaluated. CPHEAgNPs were predominantly spherical (size range of 4-32 $\mathrm{nm}$ ) with face-centered cubic phase and crystalline conformation pattern revealed by selected area electron diffraction, while EDX analysis showed the presence of
\end{abstract}

A. Lateef, M. A. Azeez, T. B. Asafa, T. A. Yekeen, A. Akinboro, I. C. Oladipo: Nanotechnology Research Group $\left(\mathrm{NANO}^{+}\right)$.

Musibau A. Azeez

maazeez@lautech.edu.ng

1 Department of Pure and Applied Biology, Ladoke Akintola University of Technology, PMB 4000, Ogbomoso, Nigeria

2 Department of Mechanical Engineering, Ladoke Akintola University of Technology, PMB 4000, Ogbomoso, Nigeria

3 Department of Science Laboratory Technology, Ladoke Akintola University of Technology, PMB 4000, Ogbomoso, Nigeria

4 Department of Chemical Sciences, Osun State University, Osogbo, Nigeria

5 Department of Microbiology, University of KwaZulu-Natal, Private Bag X01, Scottsville, Pietermaritzburg 3209, South Africa

6 Microscopy and Microanalysis Unit, School of Life Sciences, University of KwaZulu-Natal, Private Bag X01, Scottsville, Pietermaritzburg 3209, South Africa silver as a prominent metal. The synthesized nanoparticles effectively inhibited multidrug-resistant isolates of Klebsiella pneumonia and Escherichia coli at a concentration of $40 \mu \mathrm{g} / \mathrm{ml}$, and enhanced the activities of cefuroxime and ampicillin in synergistic manner at $42.9-100 \%$ concentration, while it completely inhibited the growth of E. coli, K. pneumoniae, Streptococcus pyogenes, Staphylococcus aureus, Pseudomonas aeruginosa, Aspergillus flavus, Aspergillus fumigatus and Aspergillus niger as additive in emulsion paint. The antioxidant activities of the CPHEAgNPs were found to be excellent, while highly potent larvicidal activities against the larvae of Anopheles mosquito at $10-100 \mu \mathrm{g} / \mathrm{ml}$ concentration were observed. Our study demonstrated for the first time the utility of CPHE in the biosynthesis of CPHE-AgNPs with potential applications as antimicrobial and larvicidal agents, and paint additives for coating material surfaces to protect them against microbial growth while improving their shelf life.

Keywords CPHE-AgNPs · Antimicrobial activity · Multidrug resistance Paint additive . Antioxidant . Larvicidal

\section{Introduction}

Biosynthesis of nanoparticles of metals such as gold, silver, zinc, copper, platinum and palladium has received great attention from researchers all over the world. This is due to their wide application in medical and pharmaceutical fields, especially as ingredients of most consumer products like shampoo, soaps, detergents, shoes, cosmetics and toothpastes [1]. Green chemistry has become an expanded area of nanotechnology for a number of reasons which include its low cost, less demanding and eco-friendly 
nature that is devoid of use of hazardous chemicals and procedures. The advent of green technology into the synthesis of nanoparticles has greatly revolutionized the field of nanotechnology. Firstly, it has opened up the possibility of using biomolecules/substances of diverse origin in its synthesis and secondly, it has widened its applicability in different areas of human endeavors. Utilization of green synthesized nanoparticles transverses medical and biomedical applications to solving environmental problems such as land and water pollution, through material engineering to applications in agriculture.

Quite a number of biological macromolecules/substances have been employed as capping and stabilizing agents for the green synthesis of nanoparticles. For instance, metabolites of some arthropods have been used for green synthesis of nanoparticles [2-5]. In several studies, metabolites and enzymes of microbial origin (fungi and bacteria), even whole microbes have been used in the synthesis of nanoparticles [6-11], while many others have reported the synthesis of nanoparticles by employing extracts from various parts of the plants such as seeds, fruits, flowers, leaves, stem and roots [12-19]. Kaviya et al. [20], Njagi et al. [21] and Roopan et al. [22] synthesized AgNPs using Sorghum spp bran extract, Citrus cinensis peel extract and Cocos nucifera coir, respectively, suggesting the usefulness of agro-wastes in green nanotechnology. Most recently, the usefulness of Cola nitida pod, seed and seed shell for the green synthesis of AgNPs has been demonstrated in our laboratory [23, 24].

Cocoa (Theobroma cacao) is one of the key economic crops cultivated in Nigeria. As the third largest producer of cocoa in Africa and one of the highest cocoa producer in the world, the production capacity of Nigeria was reported to have reached about 385,000 tonnes per annum on the cultivable area of 966,000 ha with an appreciable increase of about 215,000 from year 2000 production level [25, 26]. The implication of this is that as the cocoa production industry is expanding, so also the cocoa pod husk (CPH) which is the by-product of cocoa processing that account for 52 to $76 \%$ of the cocoa pod wet weight [27]. Cocoa is the principal ingredient of chocolate and other derived products such as cocoa liquor, cocoa butter, cocoa cake and cocoa powder, whereas the abundantly produced cocoa pod husks as waste in cocoa plantations during the extraction of cocoa beans are often discarded as of no market value. However, to create valuable products, cocoa pod husks have been explored as food antioxidants [28], dietary fibers [29], animal feed [30], as a precursor in the activated carbon production [31], fertilizer [32] and thermoplastic polyurethane composites [33]. It has also been investigated for use in the production of enzyme, with resultant improvement of the nutritional quality of the husk through fungal solid substrate fermentation [34].
The need to find alternative usage for agro-wastes motivated the present investigation into the biotechnological potential of cocoa pod husk extract (CPHE) in green chemistry for the synthesis of CPHE-AgNPs. Therefore, the present study was designed to explore the utility of CPHE in the synthesis of CPHE-AgNPs, evaluation of the antioxidant activities, mosquito larvicidal activities, and antimicrobial potentials of the synthesized nanoparticles against multidrug-resistant clinical bacteria. In addition, the usefulness of the synthesized CPHE-AgNPs as antimicrobial additive in emulsion paint was demonstrated. To the best of our knowledge, this report is the first of its kind on the use of cocoa pod husk extract (CPHE) for the synthesis of CPHE-AgNPs.

\section{Materials and methods}

\section{Collection and processing of cocoa pods}

Fresh cocoa fruits were obtained from Ipetumodu, Osun State, Nigeria. They were brought to the laboratory and thoroughly washed to remove dirt and other extraneous substances. The pods were split opened with the pod husk and beans separated. The pod husks were first transformed into chips and then air dried for seven days at room temperature $\left(30 \pm 2{ }^{\circ} \mathrm{C}\right)$. The pod husk chips were milled into powder with the aid of electric blender (Fig. 1).

\section{Preparation of cocoa pod husk extract}

Cocoa pod husk extract (CPHE) was obtained following the methods of Lateef et al. [23] by weighing $0.1 \mathrm{~g}$ of the powder and suspended in $10 \mathrm{ml}$ of distilled water, and heated in water bath at $60{ }^{\circ} \mathrm{C}$ for $1 \mathrm{~h}$. The extract was filtered using Whatman No. 1 filter paper and then centrifuged at $4000 \mathrm{rpm}$ before the collection of the final clear extract (CPHE), which was stored at $4{ }^{\circ} \mathrm{C}$ for further use.

\section{Green synthesis of CPHE-AgNPs and characterization}

The CPHE prepared was used to synthesize CPHE-AgNPs using the protocol previously described [23, 24]. To $40 \mathrm{ml}$ of $1 \mathrm{mM}$ silver nitrate $\left(\mathrm{AgNO}_{3}\right), 1 \mathrm{ml}$ of the extract was added at room temperature $\left(30 \pm 2{ }^{\circ} \mathrm{C}\right)$ and the reaction mixture was allowed to stand for some minutes. A change in color of the reaction mixture was visually observed, followed by the measurement of its absorbance spectrum using UV-visible spectrophotometer (Cecil, USA) operated at the range of $200-800 \mathrm{~nm}$. FTIR spectroscopy analysis was carried out on the synthesized CPHE-AgNPs 


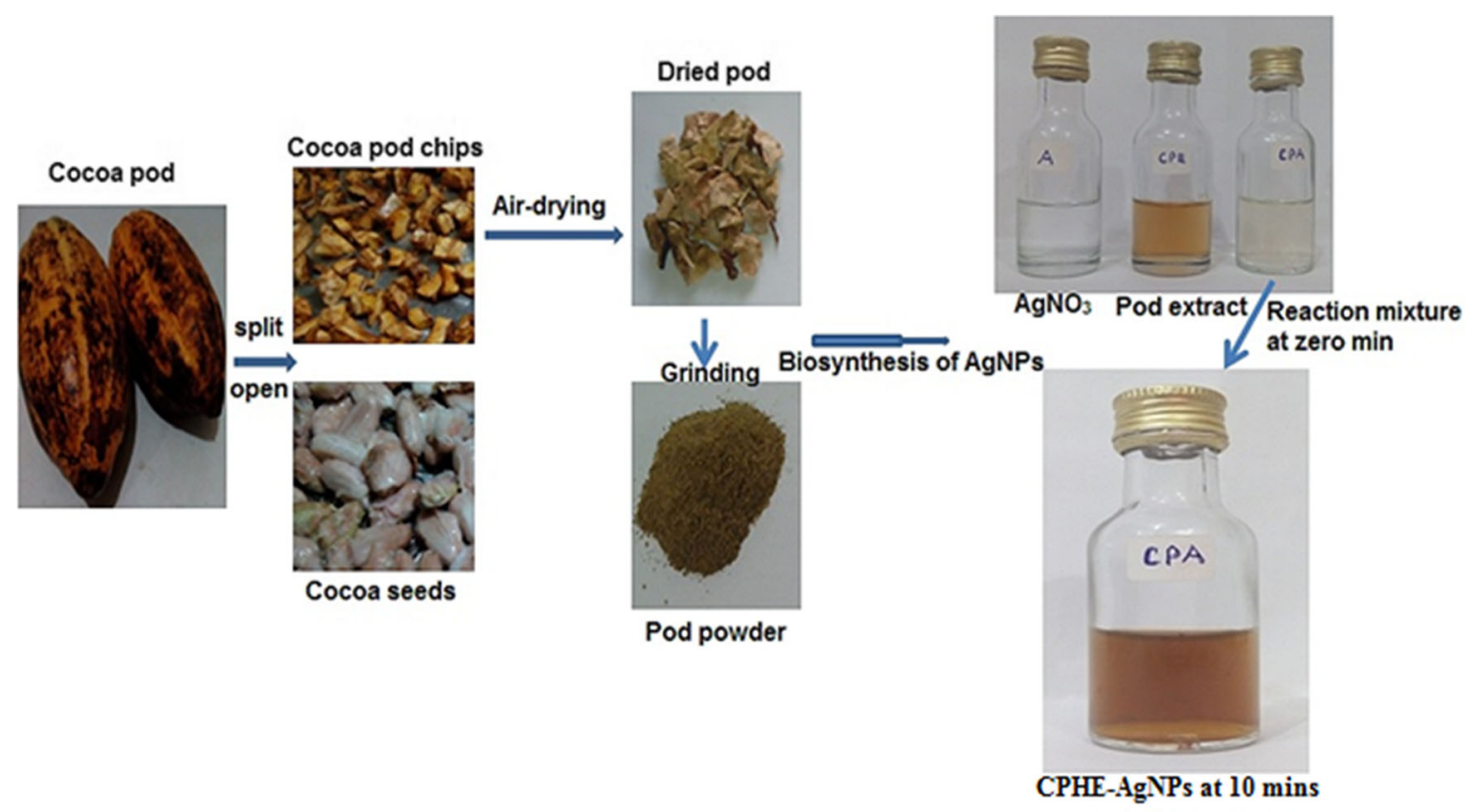

Fig. 1 Green biosynthesis of CPHE-AgNPs using the cocoa pod husk extract

using IRAffinity-1S Spectrometer to identify the functional groups of the various biomolecules that took part in the green synthesis. Transmission electron microscopy (TEM) and EDX of the synthesized CPHE-AgNPs were conducted to determine the size, morphology, nature and their elemental composition. For TEM analysis, the colloidal sample was placed on a 200 mesh hexagonal copper grid $(3.05 \mathrm{~mm}$ ) (Agar Scientific, Essex, UK) coated with $0.3 \%$ formvar dissolved in chloroform. The grids were dried before viewing under TEM model JEM-1400 (JEOL, USA) which was operated at $200 \mathrm{kV}$ to obtain the micrographs.

\section{Antimicrobial activities of the synthesized CPHE-AgNPs}

CPHE-AgNPs' antibacterial properties against clinical isolates of Escherichia coli and Klebsiella pneumonia obtained from LAUTECH Teaching Hospital, Ogbomoso were investigated using agar diffusion method as previously described $[5,10,23,24]$. The culture broth was obtained through overnight growth in peptone water and this was used to seed the freshly prepared plates of Mueller-Hinton Agar (Lab M Ltd., UK). Thereafter, plates were bored with the aid of cork borer, and $100 \mu \mathrm{l}$ of the graded concentrations of CPHE-AgNPs was introduced into the wells. This was subsequently followed by incubation at $37{ }^{\circ} \mathrm{C}$ for $24 \mathrm{~h}$, after which zones of inhibition were measured.

\section{Antibacterial susceptibility test}

The drug susceptibility of test isolates was carried out as previously demonstrated $[35,36]$. The isolates were tested on the discs (Abtek Biologicals Ltd., UK) impregnated with antibiotics containing $(\mu \mathrm{g})$ : ceftazidime (Caz), 30; cefuroxime (Crx), 30; gentamicin (Gen), 10; ceftriaxone (Ctr), 30; ofloxacin (Ofl), 5; augmentin (Aug), 30; erythromycin (Ery), 30; and cloxacillin (Cxc), 5 for Grampositive isolates. The Gram-negative isolates were tested against antibiotics $(\mu \mathrm{g})$ : ceftazidime (Caz), 30; cefuroxime (Crx), 30; gentamicin (Gen), 10; ampicillin (Amp), 10; ofloxacin (Ofl), 5; augmentin (Aug), 30; nitrofurantoin (Nit), 300; and ciprofloxacin (Cpr), 5. After incubation at $37{ }^{\circ} \mathrm{C}$ for $48 \mathrm{~h}$, the zones of inhibition were measured and interpreted [36] taking into cognizance of the recommended breakpoints [37].

\section{Antimicrobial properties of synthesized CPHE-AgNPs as additive in paint}

The antimicrobial usefulness of CPHE-AgNPs as additive in paint was investigated as described earlier [5, 10, 23], by inoculating $19 \mathrm{ml}$ of sterilized commercially procured white emulsion paint with $1 \mathrm{ml}\left(\sim 10^{6} \mathrm{cfu} / \mathrm{ml}\right)$ of $18-\mathrm{h}$ broth cultures of $E$. coli, $K$. pneumoniae, $S$. pyogenes, Staphylococcus aureus and Pseudomonas aeruginosa. In the case of antifungal assay, 48-h broth cultures of $\mathrm{A}$. flavus, A. fumigatus and A. niger were used as inocula. 


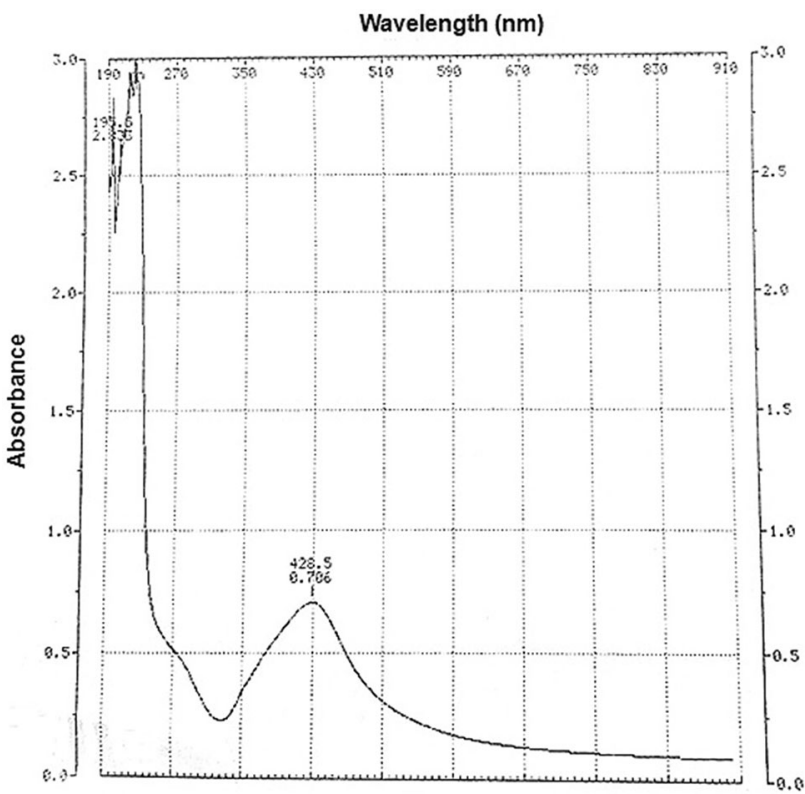

Fig. 2 The UV-vis absorption spectrum of the biosynthesized CPHE-AgNPs

The test experiment consisted of the paint and test organism, which was supplemented with $1 \mathrm{ml}$ of $100 \mu \mathrm{g} / \mathrm{ml}$ of CPHE-AgNPs. These were incubated at 37 and $30 \pm 2{ }^{\circ} \mathrm{C}$ for $48 \mathrm{~h}$ for bacteria and fungi, respectively. Thereafter, $1 \mathrm{ml}$ of the contents of each bottle was inoculated on nutrient agar for bacteria and potato dextrose agar for fungi, and incubated appropriately for $48 \mathrm{~h}$ before examination for growth.

\section{Antioxidant activities of CPHE-AgNPs}

\section{DPPH radical scavenging activity}

This was carried out using the methods of William et al. [38] by reacting one milliliter of graded concentrations of CPHE-AgNPs prepared in methanol with $4.0 \mathrm{ml}$ methanolic solution of $0.1 \mathrm{mM}$ DPPH. The mixture was shaken and left in a dark box to stand for $30 \mathrm{~min}$ at room temperature $\left(30 \pm 2{ }^{\circ} \mathrm{C}\right)$. One milliliter of absolute methanol mixed with $4.0 \mathrm{ml}$ of $0.1 \mathrm{mM}$ methanolic DPPH was also prepared and used as blank. The absorbance of the resulting solution was measured at $517 \mathrm{~nm}$ on a UV/Vis spectrophotometer (model 6405, Jenway Ltd. Essex, UK). The inhibitory percentage of DPPH was determined accordingly [39].

$\%$ inhibition $=\frac{A_{\text {blank }}-A_{\text {sample }}}{A_{\text {blank }}} \times 100$

The efficient concentration of CPHE-AgNPs that decreased the initial concentration of DPPH radical by $50 \%\left(\mathrm{IC}_{50}\right)$ was obtained by interpolation from linear regression analysis [34]. This same procedure was used for standard antioxidant compounds such as quercetin and $\beta$-carotene.

\section{Ferric reducing activity}

This was investigated using the methods of Tan et al. [40], which involved addition of $250 \mu \mathrm{l}$ of phosphate buffer

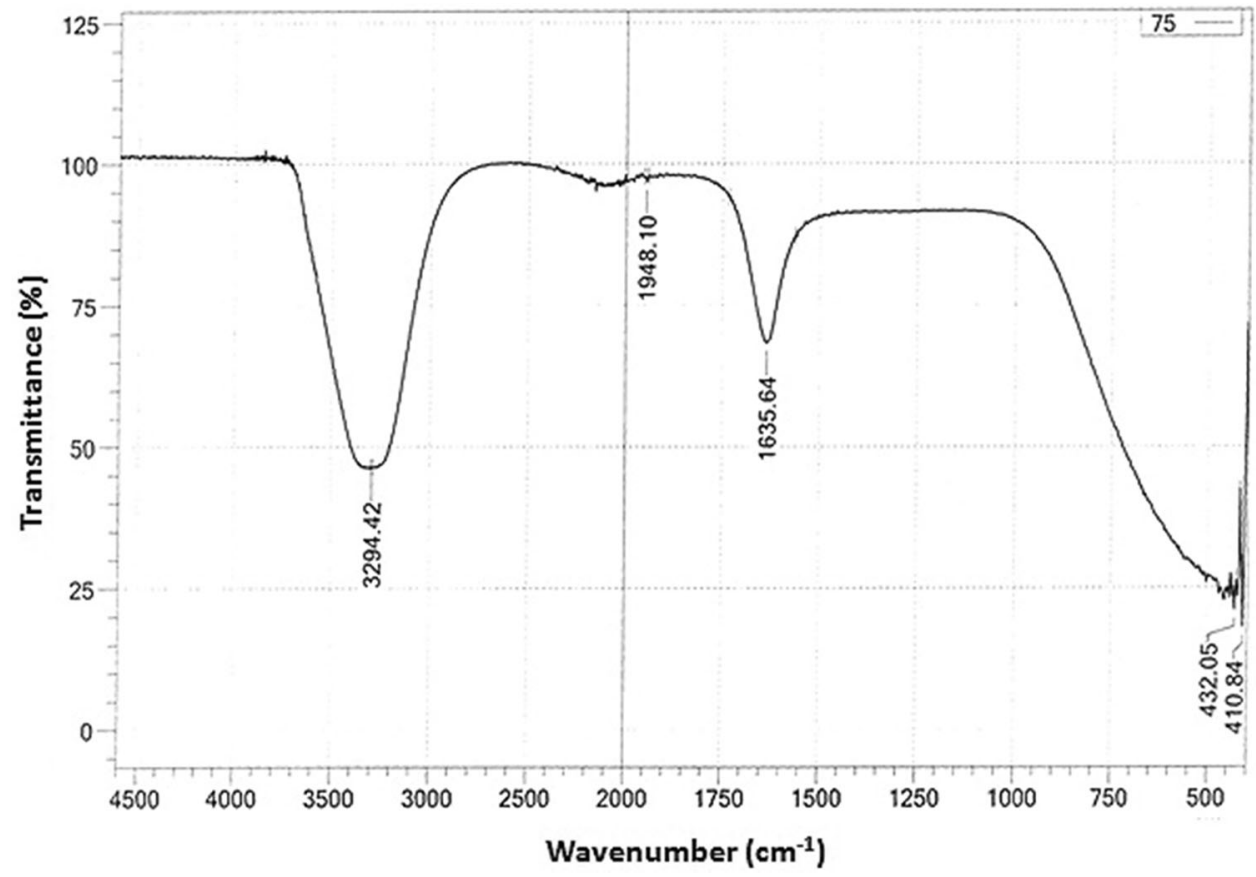

Fig. 3 The FTIR spectrum of the biosynthesized CPHE-AgNPs 
(pH 6.6) and $2.5 \mathrm{ml}$ of potassium ferricyanide to $1 \mathrm{ml}$ of different concentrations of CPHE-AGNPs prepared using distilled water. This was followed by incubation of the resulting solution at $50{ }^{\circ} \mathrm{C}$ for $20 \mathrm{~min}$. After cooling, $250 \mu \mathrm{l}$ of trichloroacetic acid was added and centrifuged for $10 \mathrm{~min}$ at $500 \mathrm{rpm}$. Then, $250 \mu \mathrm{l}$ of the supernatant with $250 \mu \mathrm{l}$ of deionized distilled water and $500 \mu \mathrm{l}$ of ferric (II) chloride were mixed thoroughly and absorbance was read at $700 \mathrm{~nm}$. The blank was prepared with all reagents without the $\mathrm{CPHE}-\mathrm{AgNPs}$.

\section{Larvicidal activity}

This was evaluated in a dose-response bioassay against the first instar anopheline larvae as previously described [10], by exposing ten Anopheles mosquito larvae to $10 \mathrm{ml}$ of graded concentrations of CPHE-AgNPs (10-100 $\mu \mathrm{g} / \mathrm{ml})$ in triplicate at room temperature $\left(30 \pm 2{ }^{\circ} \mathrm{C}\right)$. The number of dead larvae was recorded at specific intervals after exposure until total death was obtained. In the control experiment, the larvae were exposed to sterile distilled water
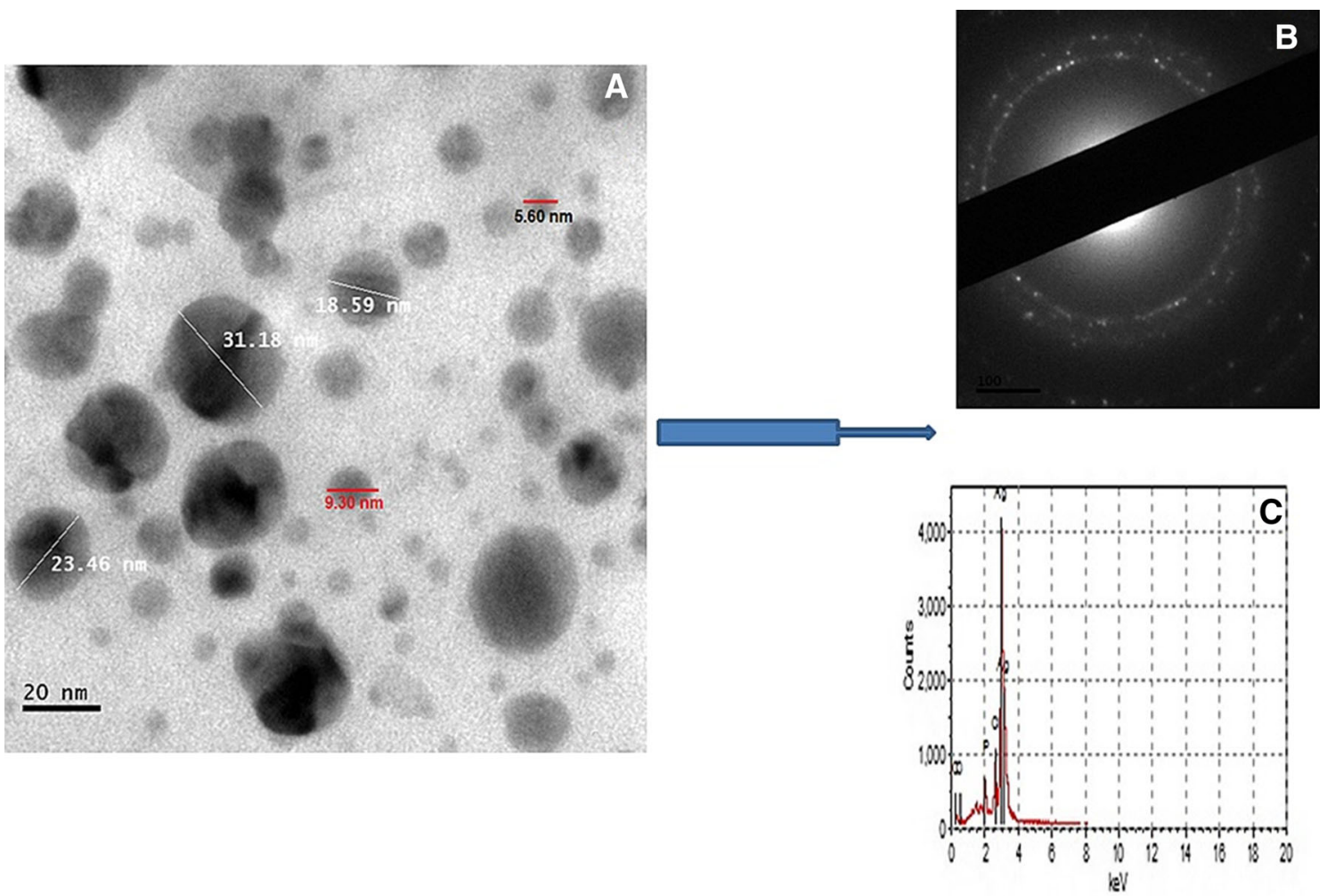

Fig. 4 Transmission electron micrograph (a), selected area electron diffraction pattern (b), and energy dispersive X-ray signal (c) of the biosynthesized CPHE-AgNPs

Table 1 The antibiotic resistance pattern of the test bacterial isolates

\begin{tabular}{llll}
\hline No of antibiotics & Isolates* & Source & Resistance pattern \\
\hline 3 & KU & Urine & Crx, Gen, Amp \\
5 & PA & Sputum & Caz, Crx, Aug, Nit, Amp \\
7 & KW & Wound & Caz, Crx, Gen, Cpr, Ofl, Aug, Amp \\
8 & EU & Urine & Caz, Crx, Gen, Cpr, Ofl, Aug, Nit, Amp \\
& SP & Sputum & Caz, Crx, Gen, Ctr, Ery, Cxc, Ofl, Aug \\
& SA & Ear & Caz, Crx, Gen, Ctr, Ery, Cxc, Ofl, Aug \\
\hline
\end{tabular}

* K, K. pneumoniae; PA, P. aeruginosa; EU, E. coli; SP, S. pyogenes; SA, S. aureus; antibiotics abbreviations are as defined under Experimental Details 


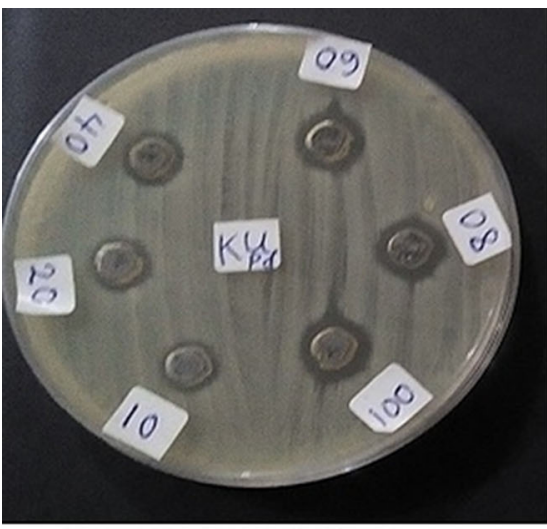

K. pneumoniae (urine)

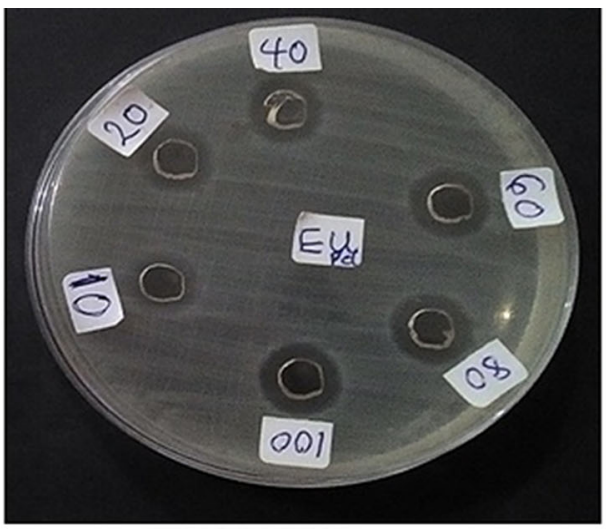

E. coli (urine)

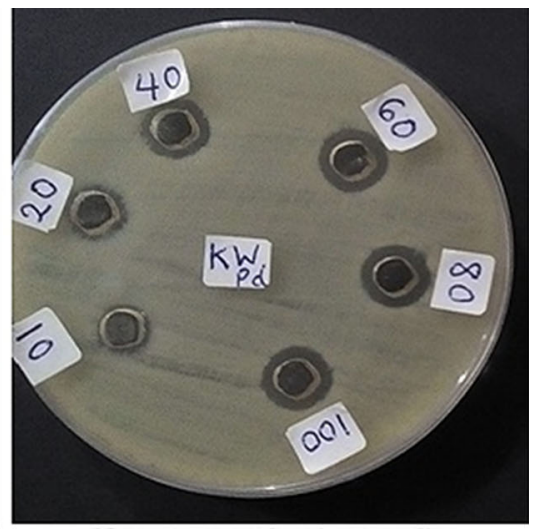

K. pneumoniae (wound)

Fig. 5 The antibacterial activities of synthesized CPHE-AgNPs against some clinical bacterial isolates

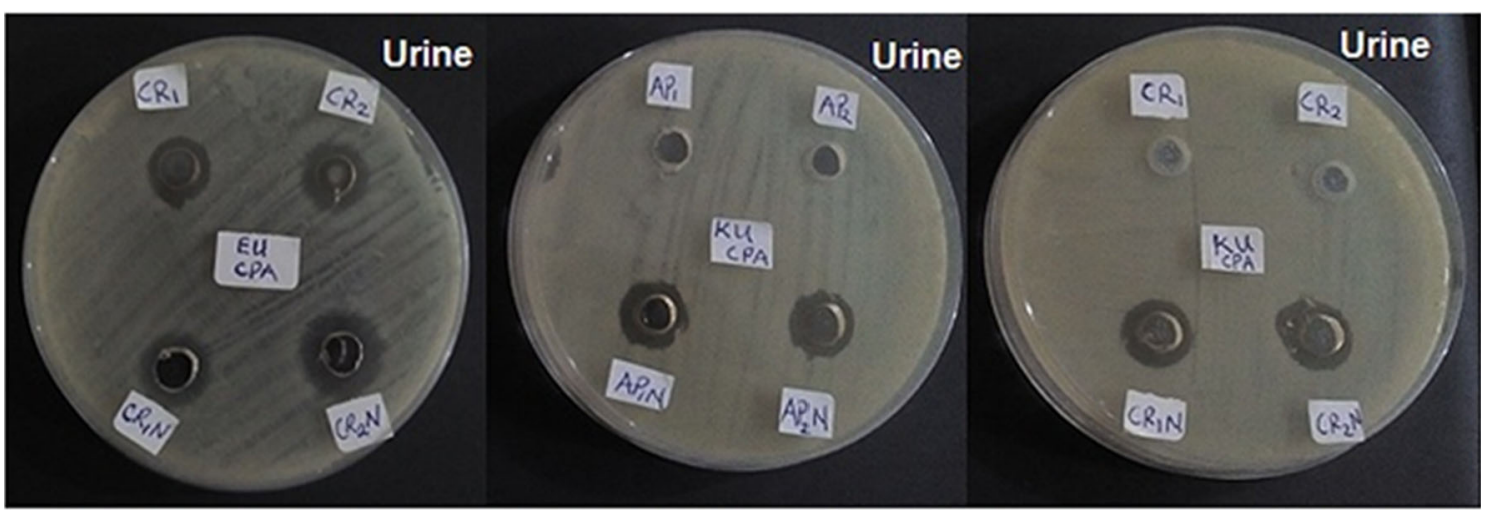

E. coli Cefuroxime

K. pneumoniae Ampicillin K.pneumoniae Cefuroxime

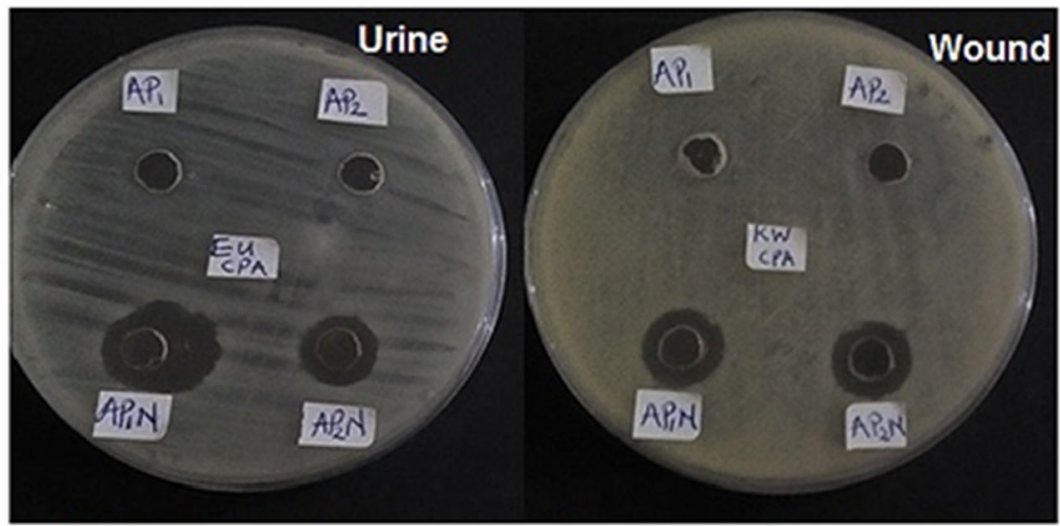

E. coli Ampicillin

K. pneumoniae Ampicillin

$1,1 \mathrm{mg} / \mathrm{ml} ; 2,500 \mu \mathrm{g} / \mathrm{ml}$ of antibiotics; $\mathrm{N}$, mixture of antibiotics and CPHE-AgNPs

Fig. 6 The synergistic activities of synthesized CPHE-AgNPs with ampicillin and cefuroxime on some clinical bacterial isolates 


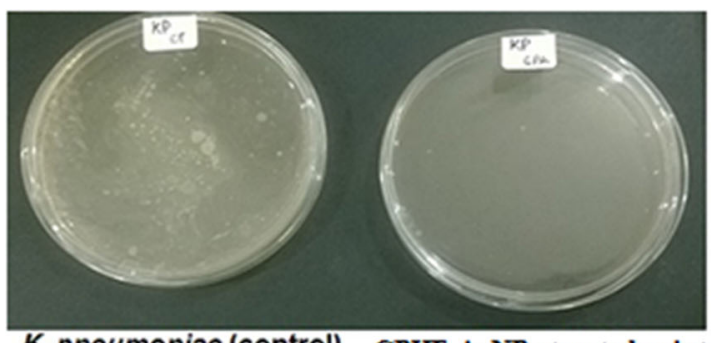

K. pneumoniae (control) CPHE-AgNPs-treated paint

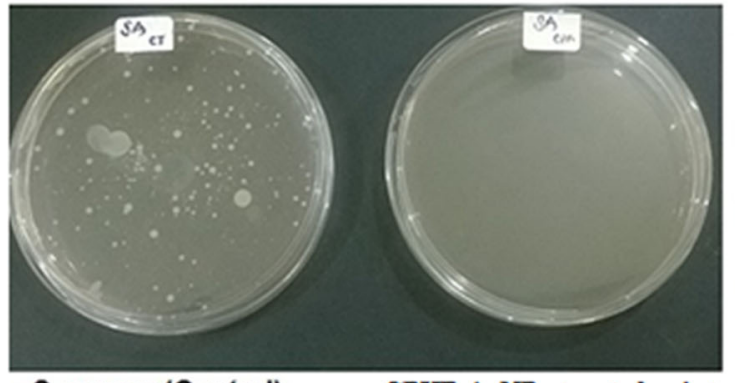

S. aureus (Control)

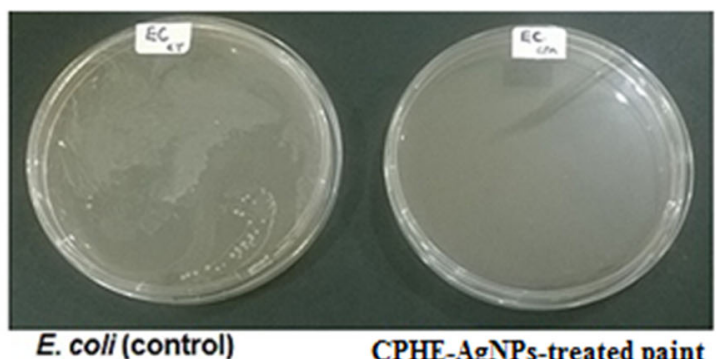

CPHE-AgNPs-treated paint

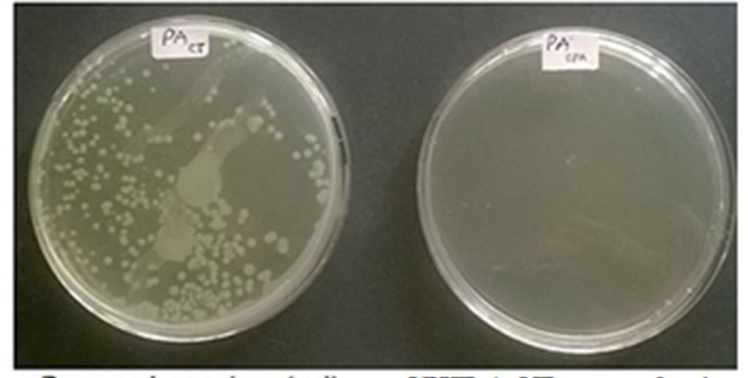

P. aeruginosa (control) CPHE-AgNPs-treated paint

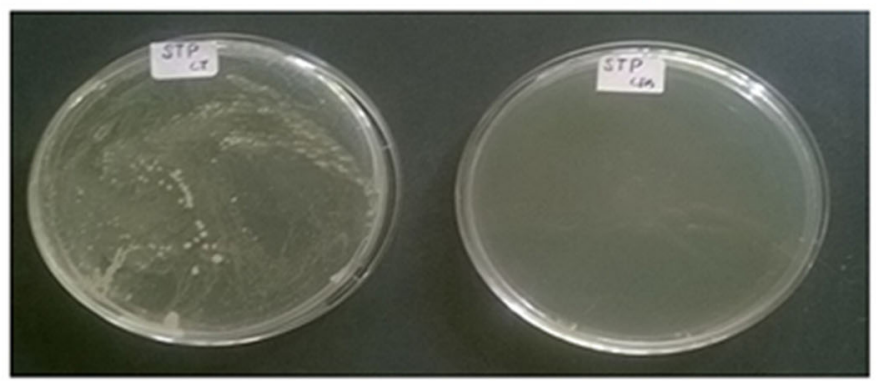

S. pyogenes (control)

CPHE-AgNPs-treated paint

Fig. 7 Antibacterial activities of synthesized CPHE-AgNPs on bacteria inoculated into emulsion paint

under the same conditions. The percentage mortality was plotted against the concentration of the CPHE-AgNPs.

\section{Results and discussion}

\section{Biogenic formation of CPHE-AgNPs}

In the present study, CPHE mediated the formation of CPHE-AgNPs within a period of 10 min, producing brown color (Fig. 1). Colloidal green-synthesized AgNP solutions exhibiting shades of color from yellowish through brown to dark brown have been reported by several authors $[5,9,10$, $23,24,41,42]$, suggesting the presence of different macromolecules in the extracts that played catalytic and stabilization roles in the formation of the particles. The maximum absorbance readings for the biosynthesized CPHE-AgNPs occurred at wavelength of $428.5 \mathrm{~nm}$ (Fig. 2). The value obtained is within the range reported for AgNPs [10, 23, 4346]. The CPHE-AgNPs exhibited a high level of stability, devoid of aggregation or deterioration.
FTIR spectrum for CPHE mediated CPHE-AgNPs (Fig. 3) manifested strong peaks at 3294.42, and $1635.64 \mathrm{~cm}^{-1}$, implicating proteins and phenolic compounds as the capping and stabilization molecules involved in the biotransformation process that produced the CPHEAgNPs. The band 3294 is typical of $\mathrm{N}-\mathrm{H}$ bond of amines, while that of 1635 is indicative of $\mathrm{C}=\mathrm{C}$ stretch of alkenes or $\mathrm{C}=\mathrm{O}$ stretch of amides [47]. In cocoa, total phenolic (determined at $45.6-46.4 \mathrm{mg}$ gallic acid equivalent of soluble phenolic), $32.3 \%$ carbohydrate, $21.44 \%$ lignin, $19.2 \%$ sugars, $8.6 \%$ protein and $27.7 \%$ minerals were previously reported [27], and they are biomolecules known to be very rich in the identified chemical bonds. Specifically, compounds such as citric acid, malic acid protocatechuic acid, p-hydroxybenzoic acid, salicyclic acid, kaempferol, linarin, resveratrol, apigenin, luteoin, crysoplenol, linoleic acid and oleic acid have been identified in cocoa pod extract [48].

The CPHE-AgNPs were fairly spherical in shape with sizes ranging from 4 to $32 \mathrm{~nm}$ (Fig. 4a), which is in agreement with those earlier reported $[5,9,10,23,24,44$, 45]. The particles were well dispersed within the organic 


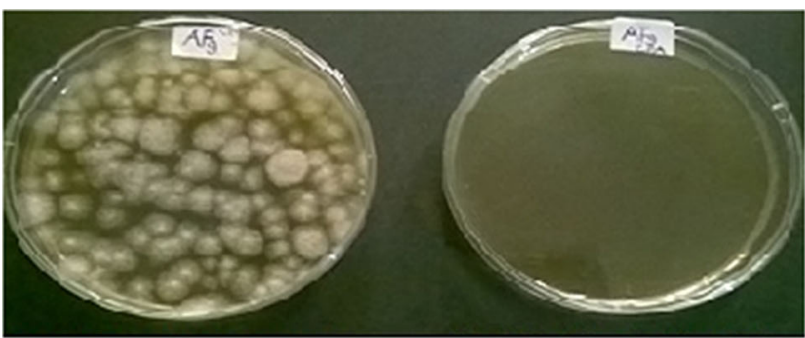

A. fumigatus (Control) CPHE-AgNPs-treated paint

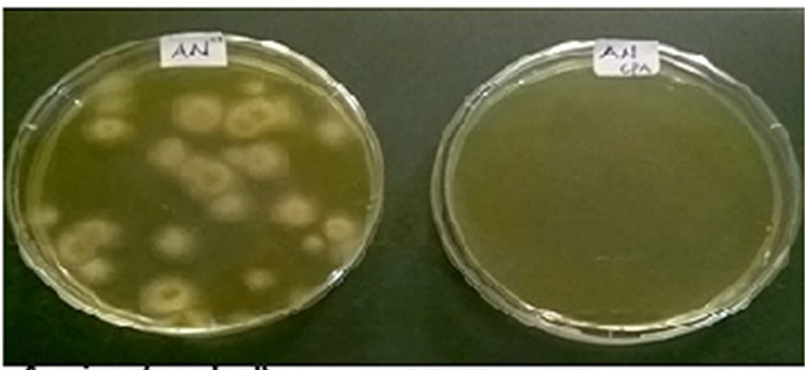

A. niger (control)
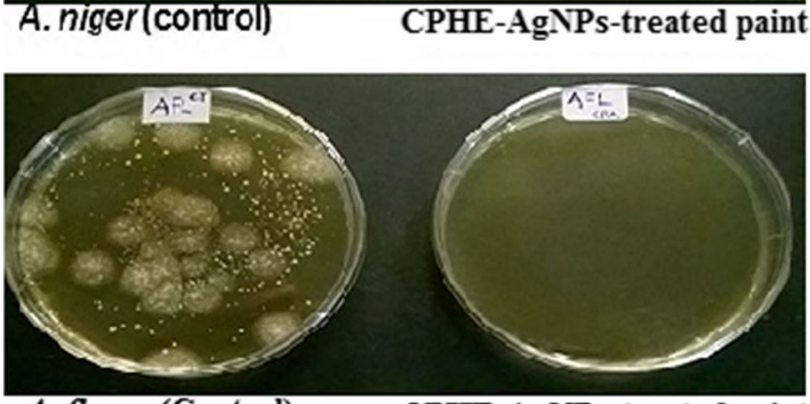

A. flavus (Control)

CPHE-AgNPs-treated paint

Fig. 8 Antifungal activities of synthesized CPHE-AgNPs on fungi inoculated into emulsion paint

matrix, indicating good stability against aggregation. The EDX patterns (Figs. 4c) showed the intense presence of silver in the CPHE-AgNPs colloidal solution [5, 10, 23, 24, $49,50]$ to the tune of $95 \%$, having the ring-like SAED pattern (Fig. 4B) associated with the face-centered cubic crystalline structure of silver [47]. It can, therefore, be inferred from these results that cocoa pod husk extract is a veritable source of biomolecules in the biogenic and ecofriendly synthesis of CPHE-AgNPs that could be of wide application in the expanding field of nanobiotechnology. This report adds to bioresource utilization of agro-wastes in the synthesis of nanoparticles.

\section{Antibacterial activities of CPHE-AgNPs against multidrug-resistant bacteria isolates}

CPHE-AgNPs strongly inhibited the growth of multidrugresistant $K$. pneumoniae and E. coli (Table 1) with the zones of inhibition of 10-14 mm (Fig. 5) at concentrations of $40-100 \mu \mathrm{g} / \mathrm{ml}$. The activities shown by the particles against these resistant isolates are of considerable importance, indicating that the particles can be deployed to reduce the growth of drug-resistant isolates that abound in the environment $[35,36,51-57]$. Similar results on the tremendous antibacterial activities of green synthesized AgNPs have been reported [5, 9, 10, 23, 24, 47, 49].

Furthermore, the CPHE-AgNPs contributed to improvement (42.9-100 \%) in the antibacterial activities of cefuroxime and ampicillin through synergy (Fig. 6). It is interesting to note that in several cases where the resistant isolates were not inhibited by the antibiotics, the CPHEAgNPs-antibiotic treatments produced outstanding growth inhibitions against strains of $K$. pneumoniae and E. coli. These results concurred with those reported in similar studies $[5,10]$. This pronounced activity is a further testimony to the potentials of CPHE-AgNPs in combating multidrug-resistant isolates, which would be of immense application in biomedical industry.

\section{Antimicrobial activities of CPHE-AgNPs in paint}

The incorporation of CPHE-AgNPs into emulsion paint led to effective inhibition of the growth of E. coli, K. pneumoniae, S. pyogenes, S. aureus $P$. aeruginosa (Fig. 7), A. flavus, A. fumigatus and A. niger (Fig. 8) as against the abundant growth on the control plates. We have previously shown that biosynthesized AgNPs can protect paint from microbial deterioration through antimicrobial activities [5, 10, 23], thus reiterating the relevance of AgNPs as antimicrobial additives in paint for applications in the built environment [58].

\section{Antioxidant activities of CPHE-AgNPs}

The DPPH-free radical scavenging activities of the biosynthesized CPHE-AgNPs were in the range of
Table 2 The ferric ion reducing activity of the biosynthesized CPHE-AgNPs

\begin{tabular}{llllll}
\hline Test material $(\mu \mathrm{g} / \mathrm{ml})^{*}$ & \multicolumn{5}{l}{ Ferric ion reducing power activity $(\%)$} \\
\cline { 2 - 6 } & 20 & 40 & 60 & 80 & 100 \\
\hline CPHE-AgNPs & 0.1614 .44 & 0.3733 .39 & 0.4641 .52 & 0.9182 .13 & 0.9383 .94 \\
Standards $(\mu \mathrm{g} / \mathrm{ml})^{*}$ & 200 & 400 & 600 & 800 & 1000 \\
Quercetin & 12.050 .13 & 20.390 .22 & 28.730 .31 & 63.950 .69 & 1001.12 \\
$\beta$-carotene & 11.530 .03 & 26.920 .07 & 19.230 .05 & 42.310 .11 & 65.380 .17 \\
\hline
\end{tabular}

* Concentration; each value is an average of three readings 
$32.62-84.50 \%$ at the investigated concentration of $20-100 \mu \mathrm{g} / \mathrm{ml}$, while those of $\beta$-carotene and quercetin were in the range of 11.11-66.67, and 43.87-74.62\% inhibitions, respectively, at the concentrations of $0.2-1 \mathrm{mg} /$ $\mathrm{ml}$. The $\mathrm{IC}_{50}$ obtained were $49.70,430$ and $710 \mu \mathrm{g} / \mathrm{ml}$ for CPHE-AgNPs, quercetin and $\beta$-carotene, respectively. In the same vein, the ferric ion reducing activities of the CPHE-AgNPs were in the range of 14.44-83.94\% for concentrations of $20-100 \mu \mathrm{g} / \mathrm{ml}$ (Table 2), whereas $\beta$-carotene had activities in the range of 11.53-65.38\%, and quercetin displayed ferric ion reduction in the range of $12.05-100 \%$ at concentrations of $0.2-1.0 \mathrm{mg} / \mathrm{ml}$. These antioxidant activities shown by the CPHE-AgNPs are similar to those previously reported [10, 23, 59, 60], with the particles manifesting greater potencies than the antioxidant standards. Previous studies have established the antioxidant capabilities of extracts obtained from cocoa pod husk [28, 34, 48]. Generally, the free radical scavenging activities of AgNPs have been attributed to the bioreductant molecules present on the surface of the nanoparticles which increase the surface areas for antioxidant activity [60]. The presence of compounds such as citric acid, malic acid, terpenoid and resveratrol has been previously attributed to antioxidant activities of cocoa pod extracts [48].

\section{Larvicidal activity of CPHE-AgNPs}

CPHE-AgNPs showed potent larvicidal activities (70-100\%) against the larvae of Anopheles mosquito at concentrations of $10-100 \mu \mathrm{g} / \mathrm{ml}$ within $2 \mathrm{~h}$ (Fig. 9) with the $\mathrm{LC}_{50}$ of $43.52 \mu \mathrm{g} / \mathrm{ml}$. The larvicidal activity of CPHEAgNPs is similar to those previously reported on the larvicidal activities of some plant and bacterial extractmediated AgNPs on Anopheles larvae [10, 22, 61, 62]. However, in the present study, the potency of the CPHEAgNPs was found to be greater within $2 \mathrm{~h}$ of exposure than those previously reported. It can, therefore, be inferred from these results that the biosynthesized CPHE-AgNPs can find useful application in the malaria control programme by killing the larvae of the vector of Plasmodium parasites.

\section{Conclusion}

The present study has clearly demonstrated the usefulness of cocoa pod husk extract (CPHE) as a cost-effective and eco-friendly bio-resource in the green synthesis of CPHEAgNPs. The synthesized particles were fairly spherical with size ranging from 4 to $32 \mathrm{~nm}$. The highly remarkable antibacterial activities of CPHE-AgNPs and enhanced activities in synergy with antibiotics against multidrug-resistant clinical isolates of bacteria, including excellent larvicidal activities against larvae of the vector of Plasmodium parasites indicated the possibility of their exploitation in biomedical industry. Furthermore, the successful inhibition of microbial growth when used as additive in paint and very strong antioxidant activities suggests the biotechnological potential of the synthesized nanoparticles in the biomedical industry and as a coating for surfaces of materials to protect them against microbial growth while improving their shelf life. To the best of our knowledge, this report represents the first reference to cocoa pod husk extract in the green synthesis of CPHEAgNPs.

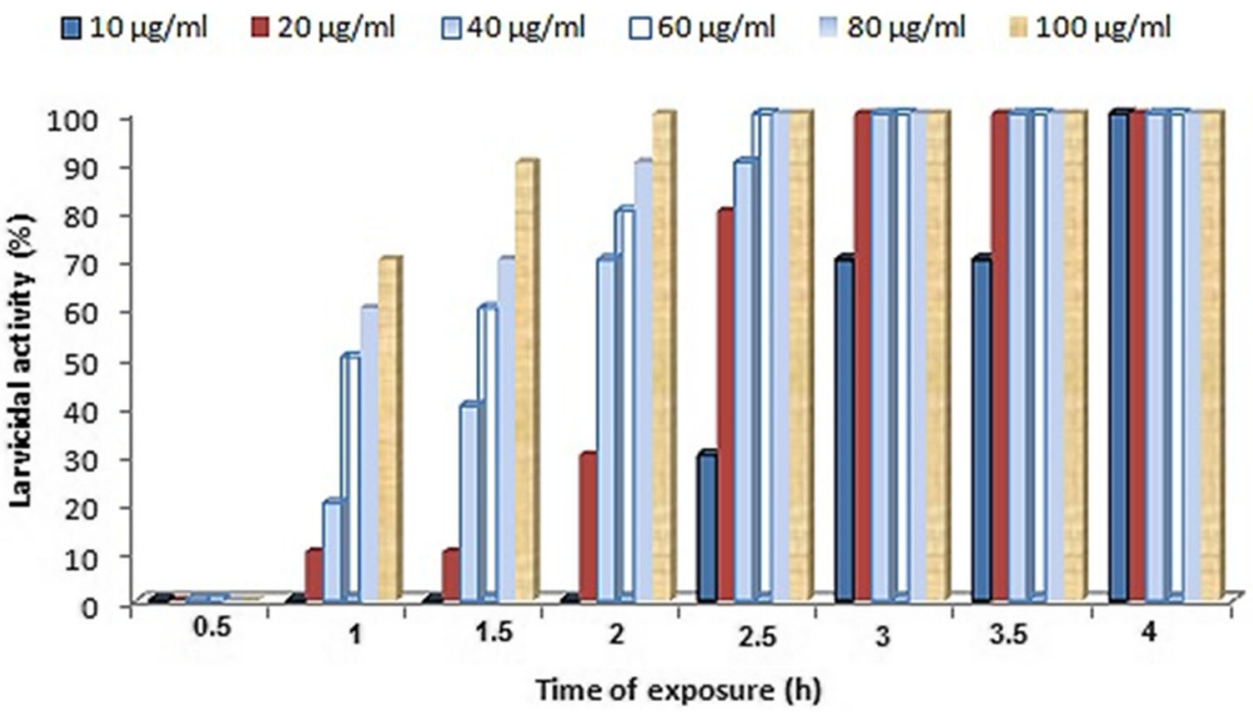

Fig. 9 Larvicidal activity of the biosynthesized CPHE-AgNPs on Anopheles mosquito larvae 
Acknowledgments AL thanked the authority of LAUTECH, Ogbomoso, Nigeria for the provision of some of the facilities used in this study. MAA gratefully thanked DBT-TWAS for Postdoctoral opportunity and visit to the Department of Chemistry, University of Pune, India (Sept, 2013-Aug, 2014).

Open Access This article is distributed under the terms of the Creative Commons Attribution 4.0 International License (http://crea tivecommons.org/licenses/by/4.0/), which permits unrestricted use, distribution, and reproduction in any medium, provided you give appropriate credit to the original author(s) and the source, provide a link to the Creative Commons license, and indicate if changes were made.

\section{References}

1. Kim, B.S., Song, J.Y.: Biological synthesis of gold and silver nanoparticles using plant Leaf extracts and antimicrobial applications. In: Hou, C.T., Shaw, J.F. (eds.) Biocatalysis and Biomolecular Engineering, pp. 447-457. Wiley, New Jersey (2010)

2. Philip, D.: Honey mediated green synthesis of silver nanoparticles. Spectrochim. Acta Part A 75, 1078-1081 (2010)

3. Sreelakshmi, C., Datta, K.K.R., Yadav, J.S., Reddy, B.V.: Honey derivatized $\mathrm{Au}$ and $\mathrm{Ag}$ nanoparticles and evaluation of its antimicrobial activity. J. Nanosci. Nanotechnol. 11, 6995-7000 (2011)

4. Obot, I.B., Umoren, S.A., Johnson, A.S.: Sunlight- mediated synthesis of silver nanoparticles using honey and its promising anticorrosion potentials for mild steel in acidic environments. J. Mater. Environ. Sci. 4, 1013-1018 (2013)

5. Lateef, A., Ojo, S.A., Azeez, M.A., Asafa, T.B., Yekeen, T.A., Akinboro, A., Oladipo, I.C., Gueguim-Kana, E.B., Beukes, L.S.: Cobweb as novel biomaterial for the green and ecofriendly synthesis of silver nanoparticles. Appl. Nanosci. (2015). doi:10.1007/ s13204-015-0492-9

6. Shivaji, S., Madhu, S., Singh, S.: Extracellular synthesis of antibacterial silver nanoparticles using psychrophilic bacteria. Process Biochem. 46, 1800-1807 (2011)

7. Rajeshkumar, S., Ponnanikajamideen, M., Malarkodi, C., Malini, M., Annadurai, G.: Microbe-mediated synthesis of antimicrobial semiconductor nanoparticles by marine bacteria. J. Nanostruct. Chem. 4, 96-102 (2014)

8. Sarsar, V., Selwal, M.K., Selwal, K.K.: Biofabrication, characterization and antibacterial efficacy of extracellular silver nanoparticles using novel fungal strain of Penicillium atramentosum KM. J. Saudi Chem. Soc. 19, 682-688 (2015)

9. Lateef, A., Adelere, I.A., Gueguim-Kana, E.B., Asafa, T.B., Beukes, L.S.: Green synthesis of silver nanoparticles using keratinase obtained from a strain of Bacillus safensis LAU 13. Int. Nano Lett. 5, 29-35 (2015)

10. Lateef, A., Ojo, S.A., Akinwale, A.S., Azeez, L., Gueguim-Kana, E.B., Beukes, L.S.: Biogenic synthesis of silver nanoparticles using cell-free extract of Bacillus safensis LAU 13: antimicrobial, free radical scavenging and larvicidal activities. Biologia $\mathbf{7 0}$, 1295-1306 (2015)

11. Jena, J., Pradhan, N., Dash, B.P., Panda, P.K., Mishra, B.K.: Pigment mediated biogenic synthesis of silver nanoparticles using diatom Amphora sp. and its antimicrobial activity. J. Saudi Chem. Soc. 19, 661-666 (2015)

12. Dhand, V., Soumya, L., Bharadwaj, S., Chakra, S., Bhatt, D., Sreedhar, B.: Green synthesis of silver nanoparticles using Coffea arabica seed extract and its antibacterial activity. Mater. Sci. Eng., C 58, 36-43 (2016)
13. Reddy, N.J., Vali, D.N., Rani, M., Rani, S.S.: Evaluation of antioxidant, antibacterial and cytotoxic effects of green synthesized silver nanoparticles by Piper longum fruit Mater. Sci. Eng. C 34, 115-122 (2014)

14. Gogoi, N., Babu, P.J., Mahanta, C., Bora, U.: Green synthesis and characterization of silver nanoparticles using alcoholic flower extract of Nyctanthes arbortristis and in vitro investigation of their antibacterial and cytotoxic activities. Mater. Sci. Eng., C 46, 463-469 (2015)

15. Anwar, M.F., Yadav, D., Kapoor, S., Chander, J., Samim, M.: Comparison of antibacterial activity of $\mathrm{Ag}$ nanoparticles synthesized from leaf extract of Parthenium hystrophorus L. in aqueous media and gentamicin sulphate: in-vitro. Drug Dev. Ind. Pharm. 41, 43-50 (2015)

16. Nayak, D., Ashe, S., Rauta, P.R., Kumari, M., Nayak, B.: Bark extract mediated green synthesis of silver nanoparticles: evaluation of antimicrobial activity and antiproliferative response against osteosarcoma. Mater. Sci. Eng., C 58, 44-52 (2016)

17. Dare, E.O., Oseghale, C.O., Labulo, A.H., Adesuji, E.T., Elemike, E.E., Onwuka, J.C., Bamgbose, J.T.: Green synthesis and growth kinetics of nanosilver under bio-diversified plant extracts influence. J. Nanostruct. Chem. 5, 85-94 (2015)

18. Logeswari, P., Silambarasan, S., Abraham, J.: Synthesis of silver nanoparticles using plants extract and analysis of their antimicrobial property. J. Saudi Chem. Soc. 19, 311-317 (2015)

19. Agharkar, M., Kochrekar, S., Hidouri, S., Azeez, M.A.: Trends in green reduction of graphene oxides, issues and challenges: a review. Mater. Res. Bull. 59, 323-328 (2014)

20. Kaviya, S., Santhanalakshmi, J., Viswanathan, B., Muthumary, J., Srinivasan, K.: Biosynthesis of silver nanoparticles using Citrus sinensis peel extract and its antibacterial activity. Spectrochim. Acta A 79, 594-598 (2011)

21. Njagi, E.C., Huang, H., Stafford, L.: Biosynthesis of iron and silver nanoparticles at room temperature using aqueous Sorghum Bran extracts. Langmuir 27, 264-271 (2011)

22. Roopan, S.M., Madhumitha, G.R., Abdul Rahuman, A., Kamaraj, C., Bharathi, A., Surendra, T.V.: Low-cost and eco-friendly phyto-synthesis of silver nanoparticles using Cocos nucifera coir extract and its larvicidal activity. Ind. Crop Prod. 43, 631-635 (2013)

23. Lateef, A., Azeez, M.A., Asafa, T.B., Yekeen, T.A., Akinboro, A., Oladipo, I.C., Azeez, L., Ajibade, S.E., Ojo, S.A., GueguimKana, E.B., Beukes, L.S.: Biogenic synthesis of silver nanoparticles using pod extract of Cola nitida: antibacterial, antioxidant activities and application as additive in paint. J. Taibah Univ. Sci. (2016). doi:10.1016/j.jtusci.2015.10.010

24. Lateef, A., Azeez, M.A., Asafa, T.B., Yekeen, T.A., Akinboro, A., Oladipo, I.C., Ajetomobi, F.E., Gueguim-Kana, E.B., Beukes, L.S.: Cola nitida-mediated biogenic synthesis of silver nanoparticles using seed and seed shell extracts and evaluation of antibacterial activities. BioNanoSci. 5, 196-205 (2015)

25. Franzen, M., Mulder, M.B.: Ecological, economic and social perspectives on cocoa production worldwide. Biodivers. Conserv. 16, 3835-3849 (2007)

26. Amao, O.D., Oni, O., Adeoye, I.: Competitiveness of cocoabased farming household in Nigeria. J. Dev. Agric. Econ. 7, 80-84 (2015)

27. Vriesmann, L.C., Amboni, R.D.D.M.C., de Oliveira Petkowicz, C.L.: Cacao pod husks (Theobroma cacao L.): Composite and hot-water-soluble pectins. Ind. Crop Prod. 34, 1173-1181 (2001)

28. Azizah, A., Nikruslawati, N., Tee, T.S.: Extraction and characterization of antioxidant from cocoa by-products. Food Chem. 64, 199-202 (1999)

29. Redgwell, R., Trovato, V., Merinat, S., Curti, D., Hediger, S., Manez, A.: Dietary fibre in cocoa shell: characterisation of component polysaccharides. Food Chem. 81, 103-112 (2003) 
30. Aregheore, E.: Chemical evaluation and digestibility of Cocoa (Theobroma cacao) byproducts fed to goats. Trop. Anim. Health Pro. 34, 339-348 (2002)

31. Adeyi, O.: Proximate composition of some agricultural wastes in Nigeria and their potential use in activated carbon production. J. Appl. Sci. Environ. Manag. 14, 55-58 (2010)

32. Agbeniyi, S.O., Oluyole, K.A., Ogunlade, M.O.: Impact of Cocoa Pod Husk Fertilizer on Cocoa Production in Nigeria. World J. Agric. Sci. 7, 113-116 (2011)

33. El-Shekeil, Y.A., Sapuan, S.M., Algrafi, M.W.: Effect of fiber loading on mechanical and morphological properties of cocoa pod husk fibers reinforced thermoplastic polyurethane. Composites. Mat. Design 64, 330-333 (2014)

34. Lateef, A., Oloke, J.K., Gueguim-Kana, E.B., Oyeniyi, S.O., Onifade, O.R., Oyeleye, A.O., Oladosu, O.C., Oyelami, A.O.: Improving the quality of agro-wastes by solid state fermentation: enhanced antioxidant activities and nutritional qualities. World J. Microbiol. Biotechnol. 24, 2369-2374 (2008)

35. Lateef, A., Davies, T.E., Adelekan, A., Adelere, I.A., Adedeji, A.A., Fadahunsi, A.H.: Akara Ogbomoso: microbiological examination and identification of hazards and critical control points. Fd Sci. Technol. Int. 16, 389-400 (2010)

36. Lateef, A., Ojo, M.O.: Public health issues in the processing of cassava (Manihot esculenta) for the production of 'lafun' and the application of hazard analysis control measures. Qual. Assur. Saf. Crops Foods. 8, 165-177 (2016)

37. Andrews, J.M.: BSAC Standardized disc susceptibility testing method (version 4). J. Antimicrob. Chemother. 56, 60-76 (2005)

38. Williams, B.W., Cuverlier, M.E., Berset, C.: Use of free radical method to evaluate antioxidant activity. Food Sci. Technol. LWT 28, 25-30 (1995)

39. Olajire, A.A., Azeez, L.: Total antioxidant activity, phenolic, flavonoid and ascorbic acid contents of Nigerian vegetables. Afr. J. Food Sci. Technol. 2, 22-29 (2011)

40. Tan, C., Xue, J., Abbas, S., Feng, B., Zhang, X., Xia, S.: Liposome as a delivery system for carotenoids: comparative antioxidant activity of carotenoids as measured by ferric reducing antioxidant power, DPPH assay and lipid peroxidation. J. Agric. Food Chem. 62, 6726-6735 (2014)

41. Kalishwaralal, K., Deepak, V., Ramkumarpandian, S., Nellaiah, H., Sangiliyandi, G.: Extracellular biosynthesis of silver nanoparticles by the culture supernatant of Bacillus licheniformis. Mater. Lett. 62, 4411-4413 (2008)

42. Shaligram, N.S., Bule, M., Bhambure, R., Singhal, R.S., Singh, S.K., Szakacs, G., Pandey, A.: Biosynthesis of silver nanoparticles using aqueous extract from the compactin producing fungal strain. Process Biochem. 44, 939-943 (2009)

43. Thirumurugan, A., Tomy, N.A., Kumar, H.P., Prakash, P.: Biological synthesis of silver nanoparticles by Lantana camara leaf extracts. Int. J. Nanomater. Biostruct. 1, 22-24 (2011)

44. Zaki, S., El-Kady, M.F., Abd-El-Haleem, D.: Biosynthesis and structural characterization of silver nanoparticles from bacterial isolates. Mater. Res. Bull. 46, 1571-1576 (2011)

45. Kannan, R.R.R., Arumugam, R., Ramya, D., Manivannan, K., Anantharaman, P.: Green synthesis of silver nanoparticles using marine macroalga Chaetomorpha linum. App. Nanosci. 3, 229-233 (2013)

46. Priyadarshini, S., Gopinath, V., Priyadharsshini, N.M., Ali, D.M., Velusamy, P.: Synthesis of anisotropic silver nanoparticles using novel strain, Bacillus flexus and its application. Colloids Surf. B: Biointerf. 102, 232-237 (2013)

47. Shankar, S., Jaiswal, L., Aparna, R.S.L., Prasad, R.G.S.V.: Synthesis, characterization, in vitro biocompatibility, and antimicrobial activity of gold, silver and gold silver alloy nanoparticles prepared from Lansium domesticum fruit peel extract. Mater. Letters 137, 75-78 (2014)

48. Karim, A.A., Azlan, A., Ismail, A., Hashim, P., Gani, S.S.A., Zainudin, B.H., Abdullah, N.A.: Phenolic composition, antioxidant, anti-wrinkles and tyrosinase inhibitory activities of cocoa pod extract. BMC complementary and Alternative Med. 14, 381 (2014)

49. Salem, W.M., Haridy, M., Sayed, W.F., Hassan, N.H.: Antibacterial activity of silver nanoparticles synthesized from latex and leaf extract of Ficus sycomorus. Ind. Crops Prod. 62, 228-234 (2014)

50. Shameli, K., Ahmad, M.B., Zargar, M., Wan Yunus, W.M.Z., Ibrahim, N.A., Sha-banzadeh, P., Ghaffari-Moghadam, M.: Synthesis and characterization of silver/montmorillonite/chitosan bionanocomposites by chemical reduction method and their antibacterial activity. Int. J. Nanomed. 6, 271-284 (2011)

51. Adewoye, S.O., Lateef, A.: Assessment of the microbiological quality of Clarias gariepinus exposed to an industrial effluent in Nigeria. Environmentalist 24, 249-254 (2004)

52. Lateef, A.: The microbiology of a pharmaceutical effluent and its public health implications. World J. Microbiol. Biotechnol. 20, 167-171 (2004)

53. Lateef, A., Oloke, J.K., Gueguim-Kana, E.B.: Antimicrobial resistance of bacterial strains isolated from orange juice products. Afr. J. Biotechnol. 3, 334-338 (2004)

54. Lateef, A., Oloke, J.K., Gueguim-Kana, E.B.: The prevalence of bacterial resistance in clinical, food, water and some environmental samples in Southwest Nigeria. Environ. Monit. Assess. 100, 59-69 (2005)

55. Lateef, A., Yekeen, T.A.: Microbial attributes of a pharmaceutical effluent and its genotoxicity on Allium cepa. Int. J. Environ. Stud. 63, 535-536 (2006)

56. Lateef, A., Oloke, J.K., Gueguim-Kana, E.B., Pacheco, E.: The microbiological quality of ice used to cool drinks and foods in Ogbomoso metropolis, Southwest. Nigeria. Internet J. Food Safety 8, 39-43 (2006)

57. Lateef, A., Yekeen, T.A., Ufuoma, P.E.: Bacteriology and genotoxicity of some pharmaceutical wastewaters in Nigeria. Int. J. Environ. Health 1, 551-562 (2007)

58. Kaiser, J.P., Zuin, S., Wick, P.: Is nanotechnology revolutionizing the paint and lacquer industry? A critical opinion. Sci. Total Environ. 442, 282-289 (2013)

59. Shanmugam, C., Sivasubramanian, G., Parthasarathi, B., Baskaran, K., Balachander, R., Parameswaran, V.R.: Antimicrobial, free radical scavenging activities and catalytic oxidation of benzyl alcohol by nano-silver synthesized from the leaf extract of Aristolochia indica L.: a promenade towards sustainability. Appl. Nanosci. (2015). doi:10.1007/s13204-015-0477-8

60. Bhakya, S., Muthukrishnan, S., Sukumaran, M., Muthukumar, M.: Biogenic synthesis of silver nanoparticles and their antioxidant and antibacterial activity. Appl. Nanosci. (2015). 10.1007/ s13204-015-0473-z

61. Priyadarshini, K.A., Murugan, K., Panneerselvam, C., Ponarulselvam, S., Hwang, J.S., Nicoletti, M.: Biolarvicidal and pupicidal potential of silver nanoparticles synthesized using Euphorbia hirta against Anopheles stephensi Liston (Diptera: culicidae). Parasitol. Res. 111, 997-1006 (2012)

62. Patil, C.D., Borase, H.P., Patil, S.V., Salunkhe, R.B., Salunke, B.K.: Larvicidal activity of silver nanoparticles synthesized using Pergularia daemia plant latex against Aedes aegypti and Anopheles stephensi and non-target fish Poecillia reticulata. Parasitol. Res. 111, 555-562 (2012) 